University of Nebraska - Lincoln

DigitalCommons@University of Nebraska - Lincoln

$2-2011$

\title{
Polarization patterning by laser-induced phase change in ferroelectric polymer films
}

Christina M. Othon

University of Nebraska-Lincoln, cothon@wesleyan.edu

Stephen Ducharme

University of Nebraska-Lincoln, sducharme1@unl.edu

Follow this and additional works at: https://digitalcommons.unl.edu/physicsducharme

Part of the Physics Commons

Othon, Christina M. and Ducharme, Stephen, "Polarization patterning by laser-induced phase change in ferroelectric polymer films" (2011). Stephen Ducharme Publications. 74.

https://digitalcommons.unl.edu/physicsducharme/74

This Article is brought to you for free and open access by the Research Papers in Physics and Astronomy at DigitalCommons@University of Nebraska - Lincoln. It has been accepted for inclusion in Stephen Ducharme Publications by an authorized administrator of DigitalCommons@University of Nebraska - Lincoln. 


\title{
Polarization patterning by laser-induced phase change in ferroelectric polymer films
}

\author{
C. M. Othon and Stephen Ducharme \\ Department of Physics and Astronomy, Nebraska Center for Materials and Nanoscience, \\ University of Nebraska-Lincoln, Lincoln, NE 68588-0299, USA
}

Corresponding author - S. Ducharme, fax 402 472-6148, email sducharme1@unl.edu

Present address for C. M. Othon: Department of Physics, Wesleyan University, Middletown, CT 06459, USA

\begin{abstract}
Polarization patterns were written on ferroelectric poly(vinylidene-trifluoroethylene) copolymer Langmuir- Blodgett films by heating into the paraelectric phase by laser illumination using two methods. In the first method, patterns were produced by direct writing by a focused continuouswave laser beam that was moved across the sample. This method affords the greatest flexibility. In the second method, the patterns were generated simultaneously with a pulsed laser using a beam interference method. This method produces highly regular patterns quickly over large areas and affords higher patterning resolution. The patterns produced by both methods could be erased and rewritten, making this technique useful for producing reconfigurable nonvolatile memories, infrared imaging sensors, or acoustic imaging transducers.
\end{abstract}

\section{Introduction}

Materials with optically patterned ferroelectric, piezoelectric, and pyroelectric response are useful for a variety of technologies, such as nonvolatile data storage, optical and infrared imaging, and ultrasonic transducers. Piezoelectric phased arrays, for example, can be used as steerable ultrasonic beam generators. Patterning by direct illumination saves steps in comparison to lithography, and works with nearly any material. Typically, the patterning is accomplished by material ablation, for example, to permanently isolate domains in ferromagnetic [1] or make repeating ferroelectric [2,3] device arrays. A less damaging method is to locally heat the film through a phase change, such as the melting point or ferroelec- tric Curie temperature [4]. Polarization patterning by laser-induced phase change has been demonstrated with ferroelectric polymer thin films, but mainly through melting, photochemical alteration, or other irreversible alterations [5, 6]. Reversible patterning, however, can be accomplished in ferroelectric films due to the reversibility of the ferroelectric-paraelectric phase transition in these materials [7]. Such patterns can be written and erased repeatedly with minimal or no degradation. Here we report the results of polarization patterning experiments accomplished by localized heating with a laser beam, which is used to depolarize selected areas of a ferroelectric polymer film.

\section{Experimental methods}

The samples for the present study were capacitors consisting of a glass substrate, aluminum thin film electrodes and a ferroelectric copolymer thin film dielectric. The substrates were 1-mm thick glass slides, on which aluminum strip electrodes were evaporated. The random copolymer of $70 \%$ vinylidene fluoride and 30\% trifluoroethylene (weightaveraged molecular weight $M_{w}$ $=100,000 \mathrm{amu}$ ) was deposited to the desired thickness by horizontal Langmuir-Blodgett deposition, as described in detail elsewhere [8,9]. Briefly, in this method a 0.1 wt.\% solution of poly(vinylidene- trifluoroethylene), or P(VDF-TrFE), (70:30) copolymer thoroughly dissolved in dimethyl sulfoxide (DMSO) was dispersed 
onto the surface of a trough of ultrapure $(18 \mathrm{M} \Omega-\mathrm{cm})$ water at room temperature. Barriers on the water's surface slowly compressed the Langmuir layer of the copolymer to a surface pressure of $5 \mathrm{mN} / \mathrm{m}^{2}$. The films were then deposited on the substrate layer by layer to a thickness of 20 nominal monolayers (MLs), or approximately $36 \mathrm{~nm}$ [10]. Another set of aluminum strip electrodes oriented orthogonal to the bottom electrodes was evaporated on top of the polymer film, resulting in several independently addressable capacitors per sample. The samples were annealed at $120^{\circ} \mathrm{C}$ for one hour to improve crystallinity. The samples used for this study differed only in the thickness and width of the aluminum electrodes, as specified below.

The distribution of electrical polarization $P$ in the samples was measured by an optical modulation method, pyroelectric scanning microscopy (PSM), which maps the spatial distribution of the pyroelectric response [11-14]. The PSM method has proven useful for studying domains and other polarization inhomogeneities in ferroelectric crystals [11, 15], ferroelectric polymer thin films $[9,16,17]$, and periodically poled nonlinear optical polymer films $[18,19]$. The PSM method consists of heating a small area of the capacitor with a laser beam, in this case the $5 \mathrm{~mW}$ output of a $633 \mathrm{~nm}$ helium-neon laser that was focused to a $17-\mu \mathrm{m}$ diameter spot with a microscope objective. The laser beam amplitude was modulated with a $2-\mathrm{kHz}$ slotted-wheel optical chopper, such that the resulting temperature modulation $(\mathrm{d} T / \mathrm{d} t)$ produced an oscillating electrical current density $\mathrm{d} P / \mathrm{d} t=(\mathrm{d} P / \mathrm{d} T)(\mathrm{d} T / \mathrm{d} t)$, which is in turn proportional to the local polarization in ferroelectric materials, such as the ferroelectric polymer films used for the present study [20]. The pyroelectric current was recorded continuously as the sample was moved with respect to the laser spot position in a raster-scan pattern consisting of line scans $20 \mu \mathrm{m}$ apart, thus producing a map, or image, of the film polarization.

\section{Experimental results}

The film polarization was patterned by two methods, sequential writing with a focused continuous-wave laser beam, and parallel array production by the interference pattern generated from mutually coherent beams from a pulsed laser [4]. Both methods patterned the sample by local heating to depolarize or melt selected areas.

In the direct writing method, the sample was depolarized by focusing the $514 \mathrm{~nm}$ green output of a continuous-wave argon ion laser to a diameter of approximately $170 \mu \mathrm{m}$ and either exposing the sample for a short time at fixed position or translating the sample at a fixed velocity. By varying the power and exposure time (or translation velocity) we could depolarize the sample by heating the polymer above its phase transition tem- perature (approximately $100^{\circ} \mathrm{C}[8]$ ); or melt the polymer by heating above the melting point (approximately $\left.150^{\circ} \mathrm{C}\right)[8,21]$. Figure $1 \mathrm{a}$ shows the polarization profile of a partially polarized film with electrodes approximately $1 \mathrm{~mm}$ wide and $50 \mathrm{~nm}$ thick prior to laser patterning. The PSM signal falls to zero outside a rectangular region defined by the crossed stripe electrodes. The PSM image shows that the polarization is uniform over the electrode area, with the exception of four reducedpolarization spots at the upper right, which were caused by previous laser depolarization, and the enhanced polarization at the edges due to the increased electric fields at the electrode edges during poling [16]. Both of these features are evident because the sample polarization was not saturated before imaging. The sample was then selectively depolarized by moving it along two mutually parallel lines at a speed of $170 \mu \mathrm{m} / \mathrm{s}$ with respect to the fixed 1-W ion laser beam. The resulting depolarization pattern (Figure $1 \mathrm{~b}$ ) shows that the polarization was decreased to nearly zero in the center of the laser beam path. The width of the depolarization regions, however, was approximately $250 \mu \mathrm{m}$, much larger than the writing beam width of $170 \mu \mathrm{m}$, largely due to lateral thermal diffusion at this relatively slow scan rate. This lateral diffusion makes fine patterning with a lowpower continuouswave laser beam impractical. To produce higher resolution, it is necessary to use exposures of much higher intensity and shorter duration. While the image in Figure $1 \mathrm{~b}$ was recorded only minutes after laser patterning, an image taken 22 hours later, Figure $1 c$, showed very little change in polarization, indicating that the polarization pattern was stable.

Depolarization patterns in the ferroelectric films were completely reversible, provided the laser power was limited such that the film temperature stayed below the melting point. This was the case for the pattern produced for Figs. 1b, c. Uniform polarization was then restored to that sample by applying $12 \mathrm{~V}(333 \mathrm{MV} / \mathrm{m})$ to the capacitor for 10 minutes at room temperature to saturate the polarization, resulting in a uniform PSM image (Figure 1d), confirming that this method of patterning is fully reversible. From a thermal model of the sample, we estimated [9] that the film at the center of the laser beam exceeded $100^{\circ} \mathrm{C}$ during patterning, as indicated schematically by the red line on the back plane of Figure $1 b$, which is sufficient to completely depolarize the center without melting the film. The fact that the polarization was reduced to zero in the center of the lines confirms this estimate. The results of the direct writing studies therefore demonstrate that it is possible to selectively depolarize a ferroelectric film with an arbitrary pattern, and yet restore the polarization fully. The film can, of course, be uniformly erased by heating it into the paraelectric phase $[7,16]$.

Interference patterning was performed by combining multiple beams from the second harmonic output 

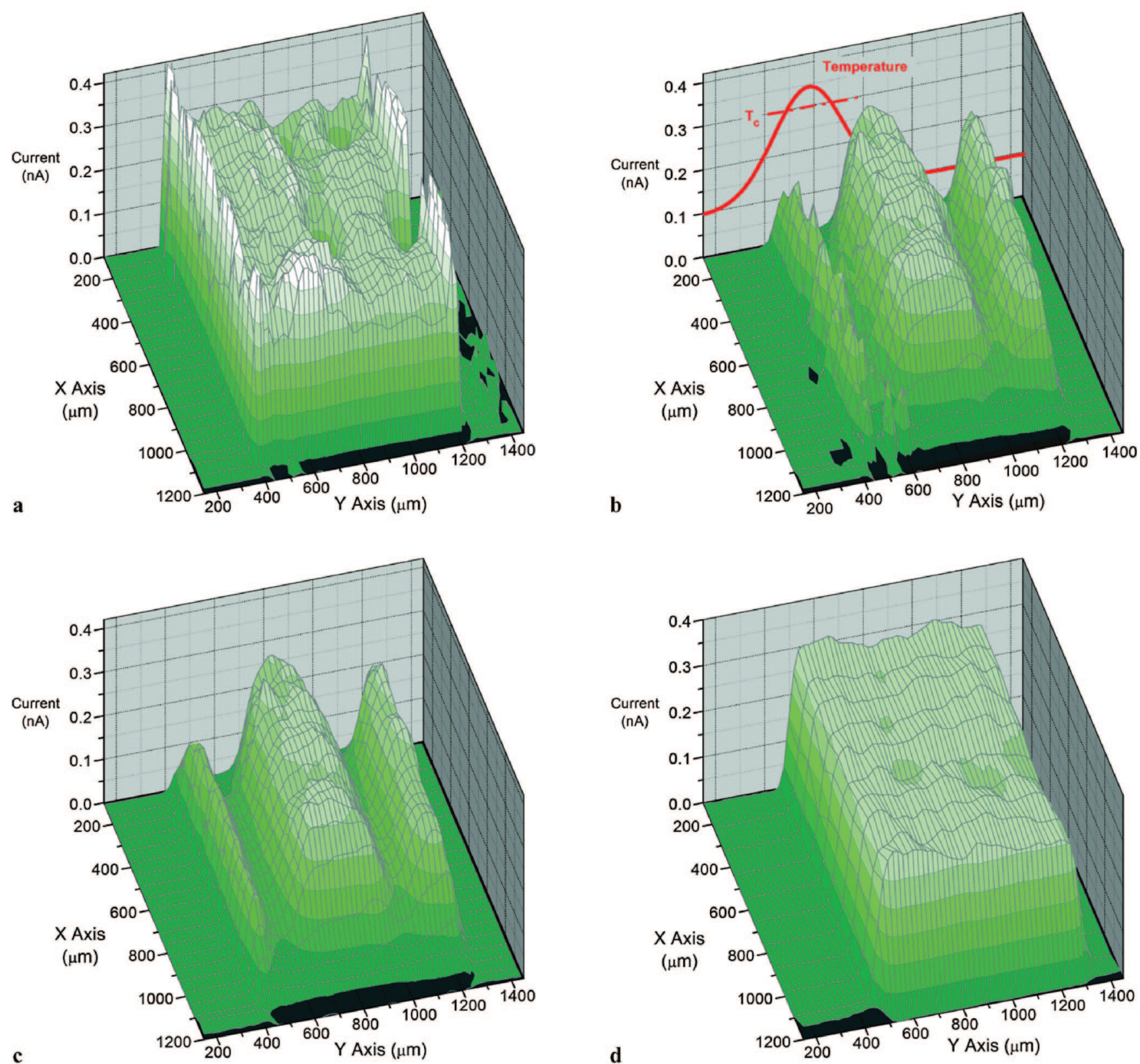

Figure 1. (a) PSM image of an incompletely poled 20-ML ferroelectric polymer capacitor before laser patterning. (b) The same sample after direct writing with a 1-W argon ion laser beam while moving the sample at a velocity of $0.17 \mathrm{~mm} / \mathrm{sec}$. The red line on the back plane shows the calculated lateral temperature profile, where $T_{C} \approx 100^{\circ} \mathrm{C}$, during patterning of the left-hand stripe. (c) The same sample after 22 hours. (d) The same sample after repoling at $12 \mathrm{~V}$ for $10 \mathrm{~min}$.

(532 nm wavelength) from a Nd:YAG laser (Continuum Surelite I). In this way, we could make regular arrays of depolarized lines spots with a single 5-ns pulse. The short pulse length minimized the effects of thermal diffusion, so that the heat was drawn out more quickly through the substrate, rather than diffusing laterally, therefore maintaining high spatial resolution in the resulting polarization pattern. One potential limitation of this method is that the film may not have time to relax into the paraelectric phase before it cools [22]. Two types of patterns were made, parallel lines using two-beam in- terference, and a triangular array using three-beam interference. The spacings were controlled by varying the angle(s) between the beams. The beam energies were controlled with a wave plate and polarizer and measured with a pyroelectric pulse energy meter (Molectron J25). Prior to patterning the film, polarization was saturated with a bias of $12 \mathrm{~V}$ for 10 minutes.

The polarization patterns produced using the twobeam interference arrangement on an LB film with electrodes $1 \mathrm{~mm}$ wide and $30 \mathrm{~nm}$ thick are shown in Figure 2 . This pattern was produced by a sequence of four 
Figure 2. PSM image of a 20-ML ferroelectric polymer capacitor after interference patterning by four $5 \mathrm{~ns}$ laser pulses of $4 \mathrm{~mJ}$ each.
Figure 3. PSM image of a 20-ML ferroelectric polymer capacitor after interference patterning by a single $11 \mathrm{~mJ}$ laser pulse, following by application of a $12-\mathrm{V}$ bias for 10 minutes.
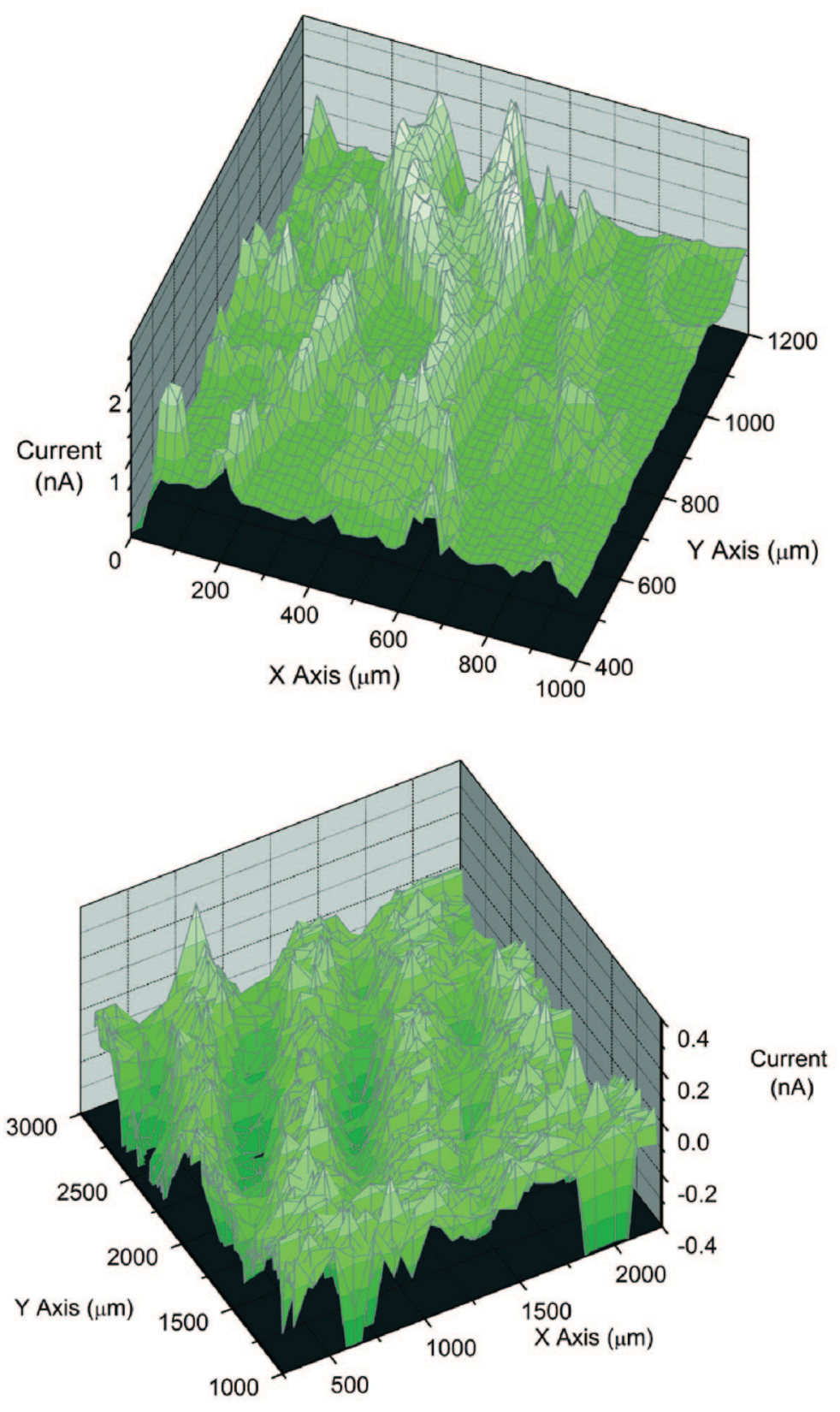

pulses of $4 \mathrm{~mJ}$ in energy, several seconds apart. The pattern is somewhat irregular, however, due to the nonuniform reflectivity of the aluminum electrodes. The sample was not completely depolarized even in the region of highest intensity, where the PSM signal was reduced by up to $60 \%$, possibly because of the long relaxation time into the paraelectric state following flash heating [22]. This pattern was also not completely erasable, even after application of a bias of $-12 \mathrm{~V}$ for 10 minutes, as shown in Figure 3, indicating that some areas of the film may have been melted. The results of the pulsed laser studies show that it is possible to selectively depolarize the ferroelectric copolymer films with very short laser pulses. This is necessary in the creation of fine patterns, because of thermal diffusion, but it requires much finer control of the pulse energy to avoid melting.

\section{Conclusions}

We have demonstrated both reversible and irreversible polarization patterning with ferroelectric polymer Langmuir-Blodgett films. Low-resolution patterns can be written slowly with a continuous-wave laser, and highresolution patterns quickly with a high-intensity pulsed laser. Because polarization patterning also modulates functional properties-piezoelectric, pyroelectric, and optical - the technique can be used to make reconfigurable optical, electronic, or electromechanical patterns suitable for use in, for example, nonvolatile memories, periodically poled waveguides, spatial light modulators, infrared imaging sensors, and acoustic imaging transducers. 
Acknowledgments - This work was supported by the National Science Foundation and by the Nebraska Research Initiative.

\section{References}

1. M. Zheng, M. Yu, Y. Liu, R. Skomski, S.H. Liou, D.J. Sellmyer, V.N. Petryakov, Y.K. Verevkin, N.I. Polushkin, N.N. Salashchenko, Appl. Phys. Lett. 79, 2606 (2001)

2. V. Dierolf, C. Sandmann, Appl. Phys. Lett. 84, 3987 (2004)

3. M. Müller, E. Soergel, K. Buse, Appl. Phys. Lett. 83, 1824 (2003)

4. A. Aktag, S. Michalski, Y. Lanping, L. Yue, S.-H. Liou, J. Appl. Phys. 99, 093901 (2006)

5. M.Wegener, J. Hesse, T.Wegener, R. Gerhard-Multhaupt, J. Appl. Phys. 91, 3193 (2002)

6. A.J. Lovinger, Macromolecules 15, 40 (1982)

7. G.T. Davis, T. Furukawa, A.J. Lovinger, M.G. Broadhurst, Macromolecules 15, 329 (1982)

8. S. Ducharme, S.P. Palto, V.M. Fridkin, in Ferroelectric and Dielectric Thin Films, vol. 3, ed. by H.S. Nalwa (Academic Press, San Diego, 2002), pp. 545-591

9. C.M. Othon, Ph.D. Dissertation, University of Nebraska, Lincoln, NE, 2005

10. M. Bai, A.V. Sorokin, D.W. Thompson, M. Poulsen, S. Ducharme, C.M. Herzinger, S. Palto, V.M. Fridkin, S.G. Yudin, V.E. Savchenko, L.K. Gribova, J. Appl. Phys. 95, 3372 (2004)
11. A. Hadni, J.M. Bassia, X. Gerbaux, R. Thomas, Appl. Opt. 15, 2150 (1976)

12. I.F. Faria, Jr., C.C. Ghizoni, L.C.M.Miranda, Appl. Phys. Lett. 47, 1154 (1985)

13. A. Hadni, Ferroelectrics 140, 25 (1993)

14. A.B. Bhattacharyya, S. Tuli, S. Kataria, IEEE Trans. Instrum. Meas. 43, 30 (1994)

15. A. Batagiannis, M. Wübbenhorst, J. Hulliger, Curr. Opin. Solid State Mater. Sci. 14, 107 (2010)

16. B.W. Peterson, S. Ducharme, V.M. Fridkin, T.J. Reece, Ferroelectrics 304, 51 (2004)

17. J. Groten, M. Zirkl, G. Jakopic, A. Leitner, B. Stadlober, Phys. Rev. B, Condens. Matter Mater. Phys. 82, 054112 (2010)

18. S. Yilmaz, S. Bauer, W. Wirges, R. Gerhard-Multhaupt, Appl. Phys. Lett. 63, 1724 (1993)

19. S. Yilmaz, S. Bauer, R. Gerhard-Multhaupt, Appl. Phys. Lett. 64, 2770 (1994)

20. A.V. Bune, C. Zhu, S. Ducharme, L.M. Blinov, V.M. Fridkin, S.P. Palto, N.N. Petukhova, S.G. Yudin, J. Appl. Phys. 85, 7869 (1999)

21. K. Koga, N. Nakano, T. Hattori, H. Ohigashi, J. Appl. Phys. 67, 965 (1990)

22. Y. Takahashi, T. Furukawa, Jpn. J. Appl. Phys. 39, 3511 (2000) 